\title{
ÉTICA Y FICCIÓN
}

Cecilia Caputo $\underline{(1)}$

Vera Waksman (2)

Resumen: El presente trabajo se propone indagar la posibilidad de la enseñanza de la ética desde la perspectiva de la construcción narrativa de sí mismo propuesta por Paul Ricoeur. En un primer momento se examinan las relaciones entre las nociones de identidad, relato y ética como práctica reflexiva. Luego, el trabajo sugiere la puesta en práctica de una propuesta de enseñanza que tenga en cuenta los relatos de ficción como mediadores necesarios para la reflexión ética, en tanto que las experiencias de pensamiento realizadas en el plano ficcional son, en términos de Ricoeur, exploraciones hechas en el reino del bien y del mal.

"El trabajo narrativo consiste en transformar nuestras experiencias y nuestros recuerdos en visiones, en formas que produzcan en el lector imágenes vívidas que lo alcancen no solamente en su inteligencia sino también en sus emociones y en las cuales se reconozca no como simple voyeur sino como un sujeto de esas visiones que el escritor le propone" (J.J. Saer, La Razón, 21/12/86)

Ante la pregunta "¿qué es el hombre?" podemos leer como respuesta en el lugar de la diferencia específica la racionalidad, la conciencia, el trabajo, la función simbólica, la neurosis. Sabemos que todas estas respuestas son certeras pero que ninguna agota el ser del hombre, si asumimos que la estructura del ser es interpretativa. Por ello y, sin olvidar el sentido de esta imposibilidad de agotamiento - sobre la cual volveremos-, quisiéramos sumar a las anteriores la respuesta de MacIntyre, según la cual el hombre "es esencialmente un animal que cuenta historias" (2001, p.266), lo que implica que necesitamos de la ficción y de la imaginación para buscar y encontrar algún sentido a nuestras vidas. Nos interesa detenernos en la relación entre dos ideas: la ficción y la ética. La primera aparece evocada en la definición de MacIntyre, por cuanto relacionamos el contar historias con la imaginación y por lo tanto con la ficción, he aquí una de las cuestiones a tratar. La segunda es, quizás, menos evidente; porque cdónde está la ética en todo esto? Apelamos entonces para explicitar esta relación a Sócrates. La máxima socrática que afirma que "una vida que sin examen no merece ser vivida" puede ser anudada al deseo de encontrar algún sentido a nuestras vidas. Este encuentro entre la ética y la ficción ha sido trabajado por Paul Ricoeur, quien desarrolla la posibilidad de pensar de otro modo la relación entre historia y vida, de manera tal que la ficción contribuya a hacer de la vida, una vida humana. Nuestro objetivo es tomar como punto de partida los estudios de Ricoeur sobre la teoría narrativa y la identidad personal para proponer un modo de concebir la práctica filosófica de la ética en el ámbito escolar.

\section{La inteligencia narrativa}


Ricoeur afirma que la literatura desarrolla un tipo de inteligencia que se puede denominar inteligencia narrativa. Esta se vincula más con la antigua sabiduría práctica y con el juicio moral que con lo que podríamos llamar el uso teórico de la razón. Ricoeur entiende que en la ética, y toma en este caso a Aristóteles, la relación entre las virtudes y la búsqueda de la felicidad permanece en un plano abstracto, "Es función de la poesía,- dice nuestro autor- bajo su forma narrativa y dramática, proponer a la imaginación y a la meditación casos imaginarios que constituyan otras tantas experiencias de pensamiento mediante las cuales aprendemos a unir los aspectos éticos de la conducta humana con la felicidad, la desgracia, la fortuna y el infortunio. Aprendemos por medio de la poesía de qué manera los cambios de fortuna resultan de tal conducta, tal como está construida por la intriga del relato."(Ricoeur, 1994, p.48) En este sentido, y dentro de la misma línea aristotélica, Ricoeur habla de una inteligencia phronética, por oposición a una inteligencia teorética o cognoscitiva.

La distinción y jerarquización entre modos de inteligencia ha desembocado, a lo largo de la historia de la filosofía -pero especialmente en la modernidad-, en un hiato insalvable entre racionalidad devenida racionalidad técnica por un lado $e$ imaginación creadora o mímesis por el otro. De todos modos, ya se puede prefigurar esta diferencia en los orígenes de la filosofía cuando consideramos la separación entre logos y mito. Si bien no hay que olvidar "la ambigüedad aparente del término mito: [ya que] en el sentido de mito sagrado, el término designa la región de héroes superiores a nosotros [...], [pero] en el sentido aristotélico mythos abarca todo el dominio de la ficción" (Ricoeur, 1995, p. 399); quizás no sea desacertado pensar que el alejamiento del mito como ficción del logos haya desencadenado un olvido de su importancia para el desarrollo y constitución de un modo de inteligencia narrativa que es central en el ámbito de la sabiduría práctica. Por eso dice MacIntyre que "la mitología, en su sentido originario, está en el corazón de las cosas" (2001, p. 266). Y por eso también, dicen Bárcena y Melich: "Nuestro logos tiene que salir de su propia lógica para atraer dentro lo que la razón filosófica occidental ha dejado afuera. Hemos de ir más allá del concepto." (2000, p.100) En consecuencia es menester recuperar el campo de la ficción para pensar la enseñanza de la ética. El texto de ficción -según Ricoeur: todas aquellas creaciones literarias que ignoran la pretensión de verdad inherente al relato histórico- propone un mundo, un mundo en el que se puede habitar y proyectar las propias posibilidades. La comprensión de sí mismo está para nuestro autor mediada por el texto, en este sentido afirma que "comprender es comprenderse ante el texto" y agrega "si la ficción es una dimensión fundamental de la referencia del texto, es también una dimensión fundamental de la subjetividad del lector. [...] La lectura me introduce en las variaciones imaginativas del ego" Pero antes de hablar de las variaciones imaginativas y del ego, es necesario hacer referencia al concepto de identidad narrativa como la respuesta ofrecida por Ricoeur al problema de la identidad personal.

\section{La identidad personal}

Habíamos partido de la pregunta por el qué del hombre, pero en el ámbito de la ética la pregunta se transforma en ¿quién soy? O más bien como se propone en el 
sexto estudio de Sí mismo como otro ¿Quién soy yo tan versátil, para que, sin embargo, cuentes conmigo? Entonces ¿cómo entender la identidad personal?

Ricoeur considera que no hay una posición inmediata del sujeto a la manera de Descartes sino que, por el contrario, es necesaria una mediación reflexiva dada por el pronombre síque acompaña a mismo en la expresión "sí mismo" Esta reflexión mostrará que la identidad subjetiva se divide en dos figuras diferentes e inseparables: la mismidad y la ipseidad, o la identidad idem y la identidad ipse. La primera es una identidad formal y sustancial, mientras que la segunda cambia con el tiempo e "implica la alteridad en un grado tan íntimo que no se puede pensar la una sin la otra" (Ricoeur, 1996, p.XIV). Al cogito cartesiano sustancializado, convertido en un qué, Ricoeur opone la pregunta por el quién; a la intemporalidad del cogito, opone la necesidad de articular la identidad personal en la dimensión temporal de la existencia humana (p.107) y de incluir la presencia del otro dentro del sí mismo. Esta dimensión temporal del sí mismo solo puede configurarse narrativamente, la pregunta quién soy requiere poder contarse a sí mismo en la forma de un relato. La identidad no es entonces un dato que hay que descubrir, la construcción de sí no puede entenderse como autoconocimiento, pues no hay transparencia consigo mismo, sino una unidad narrativa en la que debe verse "también - dice Ricoeur - un conjunto inestable de fabulación y de experiencia viva" (p.164). Fabulación no es aquí engaño o mentira, no hay genios malignos, sino construcción de una trama, articulación narrativa de acontecimientos vividos y recordados, y por lo tanto necesariamente interpretados.

En el marco de la teoría narrativa alcanza su pleno desarrollo la dialéctica de la ipseidad y de la mismidad. Al referirse a la identidad personal, Ricoeur distingue dos modelos de permanencia en el tiempo: el carácter y el mantenimiento de la palabra dada. El primero alude al conjunto de disposiciones duraderas en las que reconocemos a una persona. En este sentido, en el polo del carácter, se produce aquello que Ricoeur llama "recubrimiento del ipse por el idem", el aspecto más estable de la personalidad aparece como dominante. El segundo modelo se refiere a la constancia consigo mismo, la fidelidad a la palabra dada que ya no se deja inscribir en la dimensión del algo en general sino solo en la del quién. (p.118) Las nociones de mismidad y de ipseidad se comprenden en función de estos dos modelos de permanencia en el tiempo. Pero está claro que entre estos dos polos se da una necesaria dialéctica, un interjuego que no se reduce a definir la identidad como término medio entre dos extremos ni a presentar como resultado de la dialéctica una síntesis superadora ambos extremos. No hay tal síntesis en este modelo de identidad sino una dialéctica que es síntesis de la concordancia discordante, que mantiene siempre la tensión entre ambos polos de la identidad, como si no existiera la posibilidad de una completa y acabada posesión de sí mismo, como si la identidad fuera siempre una figura amenazada tanto por la disolución del ipse como por la cosificación del idem. Es la temporalidad la que ofrece la mediación necesaria entre ambos extremos, temporalidad que se vuelve accesible en la forma de un relato y que queda contenida en la noción de identidad narrativa.

\section{Sentidos de la ética en la escuela}


Desde este acercamiento a la perspectiva ricoeuriana sobre la identidad, podemos abordar la propuesta que nos ocupa, referida al lugar de la ética en la enseñanza. Debemos reconocer entonces que la aparición de la Formación ética y ciudadana abrió un espacio de reflexión didáctica novedoso para quienes nos dedicamos a la enseñanza de la filosofía. Si bien la ética como rama de la filosofía siempre formó parte de los programas de esta asignatura escolar reservada a los últimos años de la escuela media, la enseñanza de la misma no se concebía como diferente de la enseñanza de la filosofía. Pero la Formación ética y ciudadana no puede reducirse a la presentación del pensamiento de otros: si el término "formación" ha de tener algún sentido, éste tendrá que ver con la posibilidad de incorporar la reflexión ética a la propia vida, de transformar la ética en una experiencia de pensamiento de los alumnos.

Debemos partir entonces de una doble constatación: en primer lugar, la enseñanza de la ética tiene una particularidad dentro de la enseñanza en la medida en que se ha extendido a todos los niveles del sistema educativo; en segundo lugar esta particularidad está dada por el sentido de "formación" que se le atribuye a la disciplina. Nos interesa, entonces, proponer un sentido posible de esta formación, ligado fundamentalmente a la construcción de sí del estudiante, lo que nos llevó a reflexionar acerca de la noción de identidad que es necesario suponer en la enseñanza de la ética. A partir de una noción dinámica de identidad tomada de Ricoeur, afirmamos que no es tarea de la institución escolar el trabajar directamente sobre la subjetividad de los alumnos, en un plano ligado a las experiencias personales de los mismos, sino la de ofrecer elementos que permitan mediaciones para que cada uno reflexione sobre sí teniendo como objetivo la puesta en práctica de la máxima socrática. Entendemos, por último, que la ficción es un elemento apropiado para establecer estas mediaciones necesarias para la construcción de la identidad personal, ahora entendida como una identidad narrativa.

Proponemos entonces como sentido primordial de la formación ética en la escuela el contribuir al proceso de construcción de sí mismo del estudiante. La reflexión ética en el ámbito escolar se puede entender como esa tarea de cuidado de sí que constituye el conocimiento y la construcción de la propia identidad. Así, la noción de "formación" que acompaña a ética nada puede tener que ver con la idea de dar "forma" a una materia "informe", ni tampoco con la "fabricación" educativa que sugiere la idea de un producto mensurable y evaluable al que la educación debe dar lugar. Porque ese conocimiento de sí no lo pensamos como un autoconocimiento pedagógicamente reglado, sino como un encuentro con otro o consigo mismo a través de la experiencia de pensamiento a que puede dar lugar la reflexión o la discusión filosófica de un texto ficcional. Recuperamos aquí la expresión de la educación como "acontecimiento ético" en el sentido que le dan Bárcena y Mèlich, cuando afirman que "el aprender auténticamente humano es un aprendizaje ético porque en la aventura de aprender tiene lugar un acontecimiento, una revelación, un encuentro con otro que no soy yo" (p.162) y podemos agregar que ese otro puede ser tanto la irrupción de otro distinto de mí, tanto como ese aspecto nuevo de mí mismo que se descubre, se aparece, se crea o se percibe en la experiencia de sí dada por la práctica filosófica de la ética. 
Encarar la enseñanza de la ética desde la reflexión sobre la identidad personal exige mirar las instituciones educativas desde los supuestos que estas sostienen acerca de la identidad de sus miembros. No se requiere una perspectiva excesivamente foucaultiana para observar que el conocimiento de sí apunta primordialmente al control de sí: conocerse para mejor dominarse. Este es un primer sentido, que tiende a ver que las identidades de los estudiantes no solamente ya están dadas antes de llegar a la escuela, sino que son inmodificables. La escuela como institución tiende a ver la identidad personal de los alumnos como un dato fijo de acuerdo con ciertas determinaciones cuasi-esenciales: la nacionalidad, la clase social, la familia, la religión. En términos ricourianos diríamos que quedan atrapados en la concepción de la identidad como mismidad, sin acceder a la identidad como ipseidad. Entonces es necesario, para no caer en un recubrimiento del ipse por el idem, mantener siempre abierta la interrogación de lo que uno es, porque quienes somos como sujetos autoconscientes es siempre un juego de interpretación. Por eso creemos que la escuela debe tener en cuenta la necesidad del sujeto de "escapar, siquiera provisionalmente, a la captura social de la subjetividad"(Larrosa, 1998, p.482). Lo que no implica una sustracción de la dimensión ética del sí mismo, porque defender la posibilidad del sí mismo de estar continuamente en movimiento no significa que no pueda mantener la palabra dada.

\section{La ficción}

Dijimos que la noción de identidad narrativa supone la construcción de la propia identidad como un relato de los acontecimientos vividos. Pero, agrega Ricoeur, debido al carácter evasivo de la vida real necesitamos de la ficción para organizarla. Los relatos literarios e historias de vida se complementan porque el relato forma parte de la vida antes de exiliarse de la vida en la escritura. Entonces en lo que nos interesa hacer hincapié no es en el relato de la propia vida sino en la contribución de la ficción para la constitución de la identidad narrativa. Así dice Ricœur "debemos a las obras de ficción gran parte de la ampliación de nuestro horizonte de existencia" (1984, p.121). Esto es, la comprensión de sí, del propio pensar y de las propias valoraciones se construye necesariamente en diálogo con las historias de otros, otros que en este caso son personajes de ficción. Si pensamos que la educación es tal a partir del libro y la lectura y que nuestra capacidad para la autocomprensión pasa necesariamente por el acceso a la cultura, entonces debemos considerar como central el desarrollo del pensamiento narrativo para la reflexión sobre el sí mismo.

Es necesario precisar, sin embargo, los usos de la ficción a los que nos estamos refiriendo porque los relatos de ficción siempre han formado parte de la educación moral. Las fábulas, los cuentos tradicionales funcionaron y siguen funcionando en la práctica educativa como poderosos instrumentos de educación moral. Así el uso de la literatura es exactamente eso, un uso: la literatura, la ficción se vuelve un útil en manos de un docente que intenta transmitir una conclusión prefabricada acerca de una conducta socialmente deseable o indeseable. Podemos decir que en esos casos no se da con el texto ningún tipo de encuentro, el texto es solo el pretexto para una idea que debe ser asimilada por el otro. Este esquema, que no queda 
exclusivamente reservado a la educación más tradicional, revela una concepción de la identidad del alumno en los términos estáticos que criticábamos más arriba: el estudiante como materia inerte, vacío y predeterminado. Entender que la ficción abre un mundo implica que no es posible apropiarse de ninguna conclusión definitiva en cuanto al relato. "El acto de leer y evaluar lo que hemos leído afirma Nussbaum - es éticamente valioso precisamente porque su estructura exige tanto la inmersión como la conversación crítica, porque nos insta a comparar lo que hemos leído, no sólo con nuestra experiencia, sino con las reacciones y argumentaciones de los otros" (1997, p.34) Por eso, cuando Ricoeur afirma que no hay relato éticamente neutro, no debemos entender que el relato es una fuente de enseñanzas, sino de variaciones imaginativas, es por medio de la ficción que es posible inventar diferentes cursos de acción, ponerlos a prueba, evaluar sus consecuencias.

Entonces el desafío de la ética en la educación no es tanto el debate entre principios universalistas en pugna con un relativismo socialmente aceptado, sino más bien, una tarea de construcción de sí mismo en diálogo con experiencias y textos ficcionales. Porque, en palabras de Ricoeur, : "el mundo es el conjunto de las referencias abiertas por todos los tipos de textos descriptivos o poéticos que leí, interpreté y amé. Comprender esos textos es interpolar entre los predicados de nuestra situación todas las significaciones que, de un simple entorno (Umwelt), hacen un mundo (Welt)." (1984, p.121) "Lo que ha de interpretarse en un texto es una proposición de mundo, de un mundo tal que pueda habitarlo para proyectar allí mis posibilidades más propias." (1986, p.115)

\section{Bibliografía}

MacIntyre, A., Tras la virtud, Barcelona, Crítica, 2001.

Ricoeur, P., Educación y política, Bs.As., Docencia, 1994.

Ricoeur, P., Tiempo y narración II, México, SXXI, 1995.

Bárcena, F., Mèlcih, J.-C., La educación como acontecimiento ético, Barcelona, Paidós, 2000.

Ricoeur, P., Sí mismo como otro, México, Siglo XXI, 1996.

Larrosa, J., "Narrativa, identidad y desidentificación" en La experiencia de la lectura, Barcelona, Laertes, 1998.

Ricoeur, P., Temps et récit I, Paris, Seuil, 1984.

Nussbaum, M., Justicia poética, Santiago de Chile, Andrés Bello,1997.

Ricoeur, P., "La fonction herméneutique de la distanciation », en Du texte à l'action, Paris, Seuil, 1986. 
(1) Profesora de la UBA (Universidad de Buenos Aires). ceciliacaputo@datafull.com

(2) Profesora de la UBA (Universidad de Buenos Aires).

verawaksman@yahoo.com.ar 